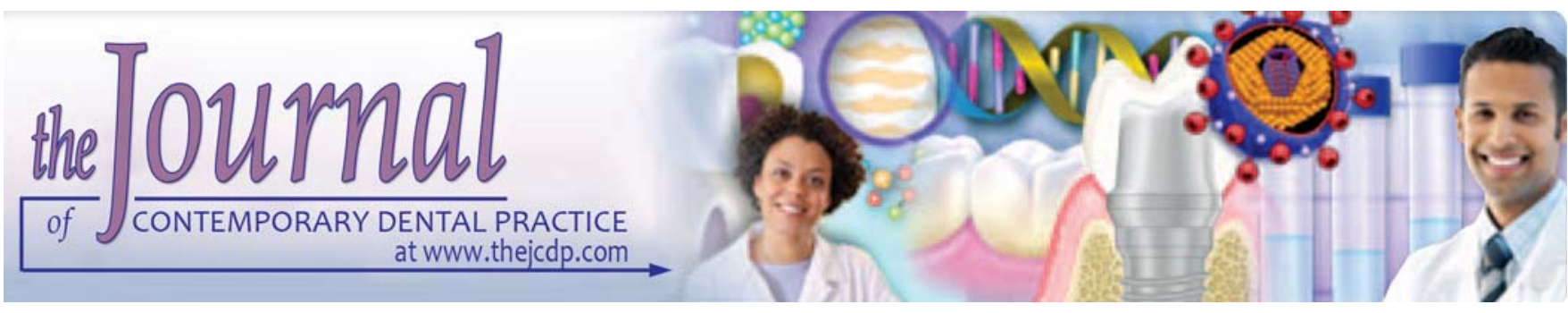

\title{
Maxillary Molar with Two Palatal Canals
}

\author{
Meghana V Prabha, Soumya Sinha, SV Kiran Kumar, Surapaneni Haragopal
}

\begin{abstract}
The endodontic treatment of maxillary molar with an aberrant root canal morphology can be diagnostically and technically challenging. ${ }^{1}$ Unusual root canal morphology in multirooted teeth is a constant challenge for diagnosis and successful endodontic treatment. Presence of extra canals, lateral canals, deltas is commonly encountered. ${ }^{2}$ This case report is presented to illustrate and describe the endodontic treatment of maxillary first molar with an unusual morphological variation of palatal root. The palatal root had two canals that appeared to unite in the apical third of the canal.
\end{abstract}

Keywords: Maxillary first molar, Dental anatomy, R oot canal.

How to cite this article: Prabha MV, Sinha S, Kumar SVK, Haragopal S. Maxillary Molar with Two Palatal Canals. J Contemp Dent Pract 2012;13(6):905-907.

\section{Source of support $\mathrm{Nil}$}

Conflict of interest: None declared

\section{INTRODUCTION}

Treatment of the entire root canal system is essential for the success of root canal treatment. Thus, it is necessary for the clinician to have knowledge of dental anatomy and its variations. $^{3}$

There are several reports in literature which relate variations in number of palatal roots and canals in maxillary first molar. They describe the existence of either one palatal root with two canal or two separate palatal roots each with its own canal. ${ }^{4}$

Black in a description of the lingual root of maxillary first molar said, 'In rare examples this root bifurcates.' Wheeler said, in the macroscopic approach to diagnosis and manipulative prognosis in endodontics, it is always worthwhile to review dental anatomy and to keep in mind the possibilities of involvement of root form and of the complete pulp cavity form of any root that is to be treated. There can be some variation in pulp cavity formation, especially the mesiobuccal root. M acroscopically, variation from single canal principle occurs least in lingual or distobuccal roots. ${ }^{5}$
A mong those who receive endodontic treatment, $96.7 \%$ of the mesiobuccal roots were found to have a single canal with a type I canal configuration, while $3.3 \%$ had two canals with a type II canal configuration. This result is in contrast to reports by others. Buhrley et al reported the prevalence of a second mesiobuccal canal when examined using traditional techniques to be $17.2 \%$, but with the use of magnifying aids, such as operating microscope the findings increased to $62.5 \%$. Stropko, in an 8-year study, found a second mesiobuccal canal in $73.2 \%$ of teeth treated endodontically by traditional means. Of these, the second mesiobuccal canal occurred as a separate canal in $54.9 \%$ of cases seen.

The distobuccal roots in the sectioned teeth as well as the teeth in the clinical phase which received endodontic treatment all had a single canal with the type I canal configuration. This is similar to the findings in studies by W ong and J acobsen. H owever, other researchers reported a contrasting result. B ond reported a case of maxillary first molar with six canals: Two in the mesiobuccal, two in the distobuccal and two in the palatal root.

The presence of additional canals in the palatal root of maxillary molars has been reported to be 2 to $5.1 \%$. Christie and Thompson speculated maxillary molars with two palatal roots may be encountered once every 3 years in a busy endodontic practice. How ever, Stephen reported a case of a maxillary first molar with two canals in the palatal root in which the canal join at the apical one-third. Although, the incidence of an extra canal in the palatal root is not high, it is important to take this variation into consideration during root canal therapy in order to ensure success. ${ }^{6}$ These extra canals must be identified and debrided to prevent endodontic failure. Even when the frequency of radicular anatomy abnormality is extremely low, dentists must consider the possibility that a tooth has extra root canals or even extra roots. ${ }^{7}$

This clinical case describes a maxillary molar with two palatal canals that appeared to unite in the apical third of the canal. 


\section{CASE REPORT}

A 35-year-old female patient reported to the department of conservative and endodontics with the chief complaint of pain in the right upper back region of the mouth since 15 days. M edical history was noncontributory. The clinical diagnosis was irreversible pulpitis.

A pretreatment radiograph was taken (Fig. 1). Local anesthesia was administered. A fter placing a rubber dam, a conventional access opening was performed. A fter removing tissues located in the pulp chamber, two orifices were observed in the palatal root. $\mathrm{K}$-file was inserted into the orifices and radiograph was taken which revealed two canals in the palatal root which join at the apical third (Fig. 2). W orking length was determined using apex locator (Root ZX, J. M orita, USA ). The working length radiograph was taken using bisecting angle technique. Root canal was prepared using crown down technique with rotary ProT aper, and all the canals were enlarged to the finishing file $F 2$. The canals were irrigated with $1 \%$ sodium hypochlorite

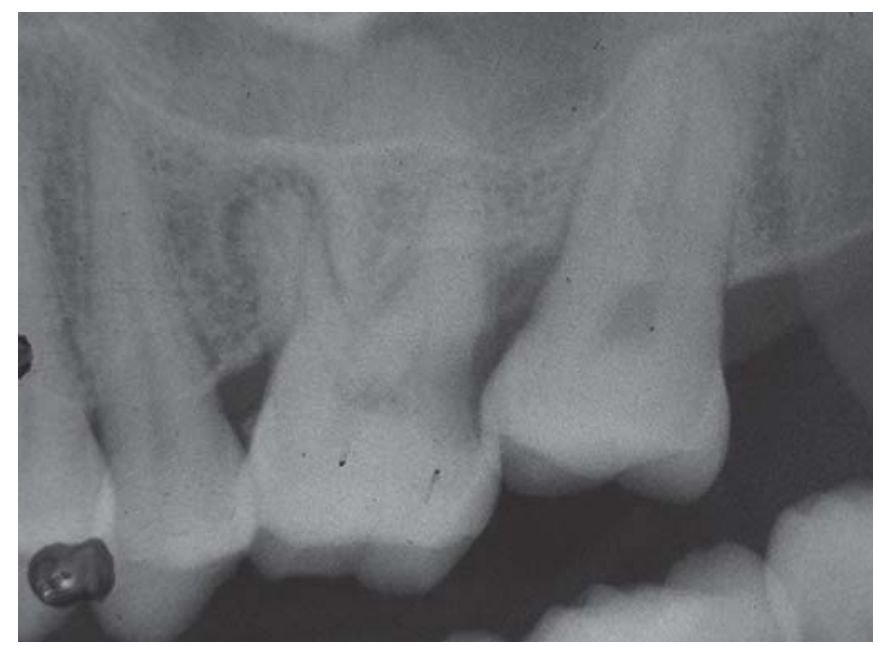

Fig. 1: Preoperative periapical radiograph

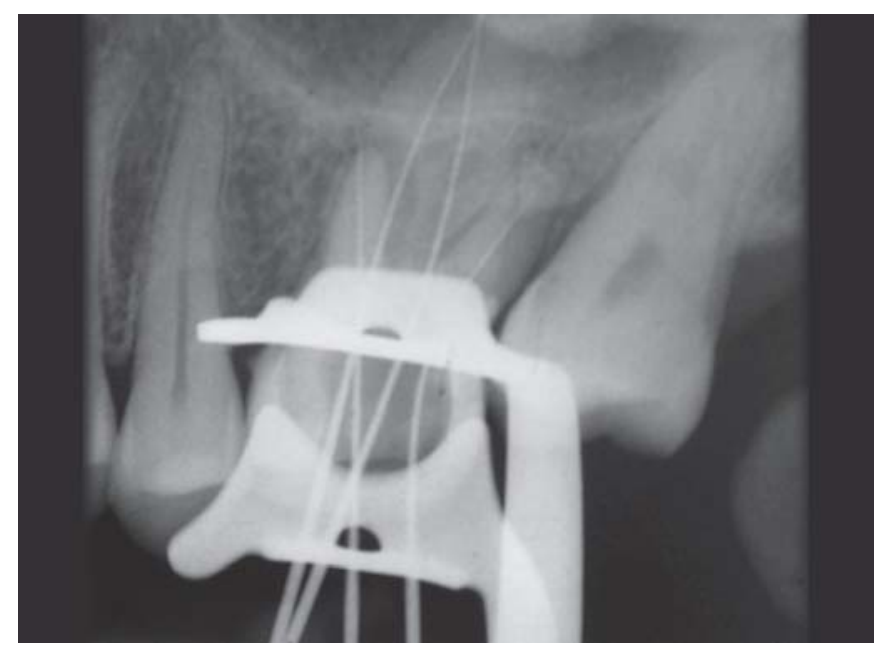

Fig. 2: Periapical radiograph showing two canals in palatal root solution, flushed with sterile saline solution and completely dried with absorbent paper points. The canals were obturated using standardized gutta-percha points and A H-26 root canal sealer (Figs 3 and 4).

\section{DISCUSSION}

In retrospect, the indistinct image of the palatal root on the preoperative radiograph should caution the author possibility of a second canal. In addition, the initial length determination radiograph revealed the file in the palatal root to be off-centered (Fig. 5). Slowey had stressed the need for further exploration when such findings occur. L ocation of the second canal was found with the aid of the radiograph which serendipitously revealed the two canal system. The assumption that this tooth had only one palatal canal stresses the importance that morphological variations are usually unexpected and when they occur we must be quick to revaluate our procedure and deal with the anomaly as it presents. $^{8}$

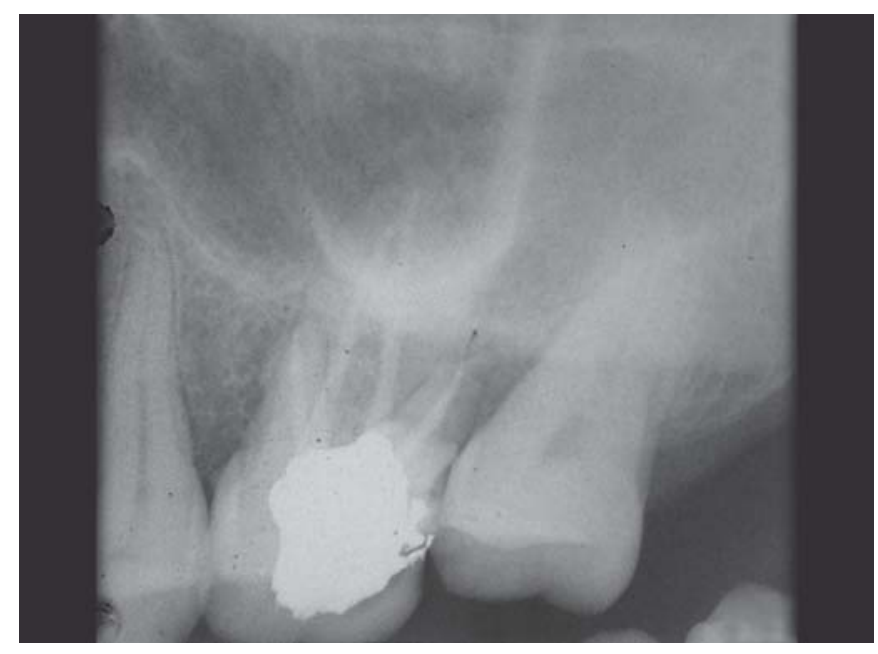

Fig. 3: Root canals filled, showing two canals in palatal root from distal angulation

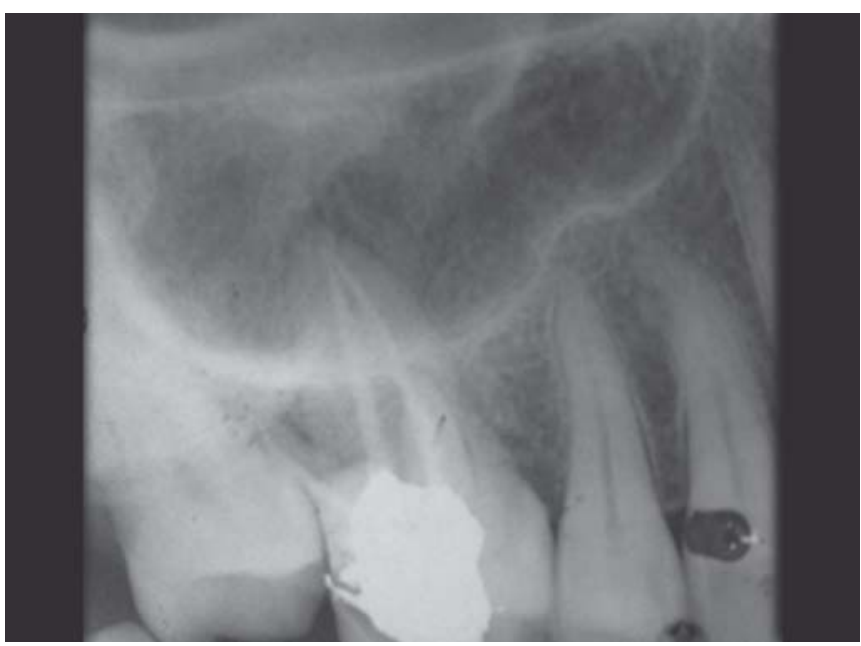

Fig. 4: Root canals filled showing two canals in palatal root from mesial angulation 


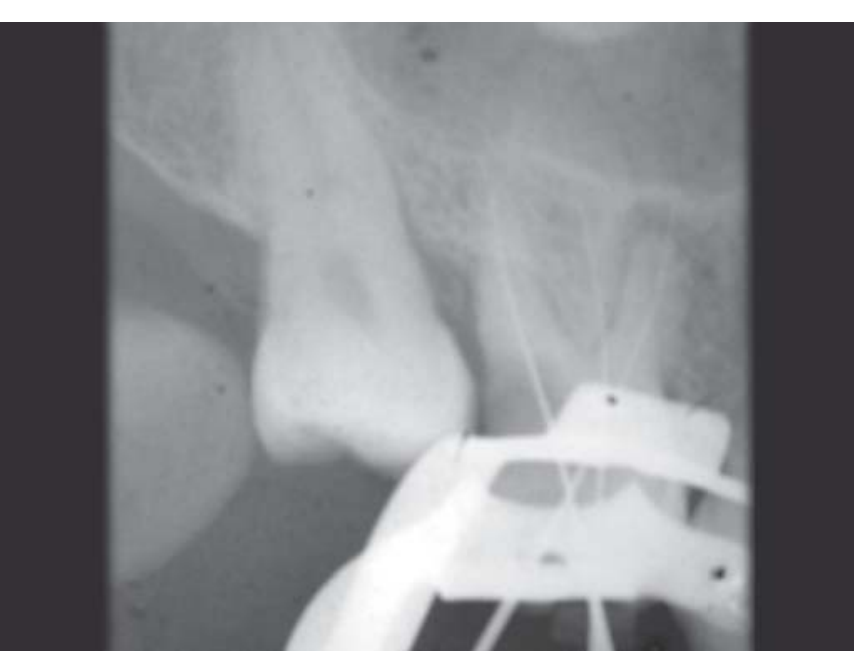

Fig. 5: Radiograph of initial length files in place. File in the palatal canal is off-centered

\section{CONCLUSION}

The root canal anatomy of each tooth in human dentition has certain common characteristics as well as numerous atypical ones that can be a road map to successful endodontic. Knowledge of existence of these variation is important for both diagnostic and treatment standpoints. Thus, it is essential to highlight the need to look for unusual morphology and additional root canals so as to achieve a good endodontic outcome.

\section{CLINICAL SIGNIFICANCE}

$V$ ariations in dental anatomy are found in all teeth. Knowledge of these variations, particularly concerning the location and treatment of all canals, is very important for the success of endodontic therapy, because the inability to find and properly treat the root canals may cause failures. ${ }^{9}$ Complete clinical and radiographic examination and a thorough knowledge of the morphology of these teeth are necessary for successful clinical results. ${ }^{10}$

\section{REFERENCES}

1. Di Fiore PM. A four rooted quadrangular maxillary molar. J Endod 1999 Oct;25(10):695-97.
2. Shigli A, A grawal A. Permanent maxillary first molar with single root and single canal: A case report of a rare morphology. J Indian Soc Pedod Prev Dent 2010 A pr-J un;28(2):121-25.

3. Baratto-Filho F, Fariniuk LF, Ferreira EL, Pecora JD. Clinical and macroscopic study of maxillary molars with two palatal roots. Int Endod J 2002 Sep;35(9):796-801.

4. Benenati FW. M axillary second molar with two palatal canals and a palatogingival groove. J Endod 1985;11(7):308-10.

5. Thews $M E, K$ emp WB, J ones CR. A berrations in palatal root and root canal morphology of two maxillary first molars. J Endod $1979 \mathrm{M}$ ar;5(3):94-96.

6. Funmilaya IM , D osumu 00 , Shaba PO, A jayi D M . Prevalence of additional canals in maxillary first molars in Nigerian population. J Contemp Dent Pract 2006;6(7)1-8.

7. Ravindranath $M$, N eelakantan $P$, Subba R ao CV. M axillary lateral incisor with two roots: A case report. Gen Dent 2011 Jan-Feb;59(1):68-69.

8. Wong M . M axillary first molar with three palatal canals. J Endod 1991;17(6):298-99.

9. Poorni S, K umar A, Indira R. M axillary first molar with aberrant canal configuration: A report of 3 cases. Oral Surg Oral Med Oral Pathol Oral Radiol Endod 2008 Dec;106(6):e62-e65.

10. A danir $\mathrm{N}$. A n unusual maxillary first molar with four roots and six canals: A case report. A ust Dent J 2007 Dec;52(4):333-35.

\section{ABOUT THE AUTHORS}

\section{Meghana V Prabha}

Postgraduate Student, Department of Endodontics and Conservative Dentistry, PM NM D ental College and Hospital, B agal kot, K arnataka India

CorrespondenceAddress 1818 O slo Ct \# 3, M undelein, IL - 60060 USA, Ph: 847-222-3760, e-mail: meghanaprabha@ hotmail.com

\section{Soumya Sinha}

A ssistant Professor, Department of Pedodontics and Preventive Dentistry, M A Rangoonwala College of Dental Sciences and Research Centre, Pune, M aharashtra, India

\section{SV Kiran Kumar}

Assistant Professor, Department of Pedodontics and Preventive Dentistry, M A Rangoonwala College of Dental Sciences and Research Centre, Pune, M aharashtra, India

\section{Surapaneni Haragopal}

A ssistant Professor, Department of Prosthodontic, G overnment Dental College and Hospital, Hyderabad, A ndhra Pradesh, India 